\title{
Consequence of one-electron oxidation and one-electron reduction for aniline
}

\author{
Ewa D. Raczyńska • Tomasz M. Stępniewski • \\ Katarzyna Kolczyńska
}

Received: 19 October 2010 / Accepted: 28 January 2011/Published online: 4 March 2011

(C) The Author(s) 2011. This article is published with open access at Springerlink.com

\begin{abstract}
Quantum-chemical calculations were performed for all possible isomers of neutral aniline and its redox forms, and intramolecular proton-transfer (prototropy) accompanied by $\pi$-electron delocalization was analyzed. One-electron oxidation $\left(\mathrm{PhNH}_{2}-\mathrm{e} \rightarrow\left[\mathrm{PhNH}_{2}\right]^{+\bullet}\right)$ has no important effect on tautomeric preferences. The enamine tautomer is preferred for oxidized aniline similarly as for the neutral molecule. Dramatical changes take place when proceeding from neutral to reduced aniline. Oneelectron reduction $\left(\mathrm{PhNH}_{2}+\mathrm{e} \rightarrow\left[\mathrm{PhNH}_{2}\right]^{-*}\right)$ favors the imine tautomer. Independently on the state of oxidation, $\pi$ - and $n$-electrons are more delocalized for the enamine than imine tautomers. The change of the tautomeric preferences for reduced aniline may partially explain the origin of the $\mathrm{CH}$ tautomers for reduced nucleobases (cytosine, adenine, and guanine).
\end{abstract}

Keywords Aniline $\cdot$ Charged radicals $\cdot \mathrm{DFT} \cdot \pi$-Electron delocalization · Prototropy · One-electron oxidation .

One-electron reduction

E. D. Raczyńska $(\bowtie)$

Department of Chemistry,

Warsaw University of Life Sciences (SGGW),

ul. Nowoursynowska 159c,

02-776 Warszawa, Poland

e-mail: ewa_raczynska@sggw.pl

T. M. Stępniewski $\cdot$ K. Kolczyńska

Interdisciplinary Department of Biotechnology,

Warsaw University of Life Sciences (SGGW),

ul. Nowoursynowska 166,

02-776 Warszawa, Poland

\section{Introduction}

Aniline is a model compound that can be used to understand the structure and physicochemical properties of many biologically active aromatic derivatives such as nucleobases (cytosine, adenine, and guanine) containing the amine group in the ring. Similar to other models of nucleobases (phenol, hydroxypyridine, aminopyridine, imidazole, purine, etc.), aniline exhibits prototropic tautomerism (Scheme 1) [1-5]. This phenomenon influences the physicochemical properties of aniline. For the neutral molecule, the enamine tautomer (1) is preferred due to strong delocalization of $\pi$-electrons. The proton transfer from the exo-amine group to the endocarbon atom destroys the aromaticity of the ring and strongly destabilizes the imine forms (2-4) in comparison to the enamine one. Usually, the imine tautomers are neglected for aniline [6]. However, investigations of many important biological transformations showed that the energetically less stable tautomer for the neutral form, with particular acidbase, electrophilic-nucleophilic, redox, or even just geometric properties, is often an active intermediate and dictates the mechanism and the product formed. For this reason, complete tautomeric equilibria should be considered for model compound to understand the mechanisms of various biochemical transformations for more complex aromatic biomolecules containing the amine group in the ring.

In this paper, we investigated the consequences of oneelectron oxidation and one-electron reduction on tautomeric equilibria for aniline and on composition of its tautomeric mixture. We considered various oxidation states of aniline, neutral $\left(\mathrm{PhNH}_{2}\right)$, oxidized $\left(\mathrm{PhNH}_{2}-\mathrm{e} \rightarrow\left[\mathrm{PhNH}_{2}\right]^{+}\right)$, and reduced state $\left(\mathrm{PhNH}_{2}+\mathrm{e} \rightarrow\left[\mathrm{PhNH}_{2}\right]^{-*}\right)$. The redox forms of aniline may be formed in the presence of oxidizing or reducing agents. They may also be generated electrochemically, photochemically, or with solvated electrons in liquid ammonia 


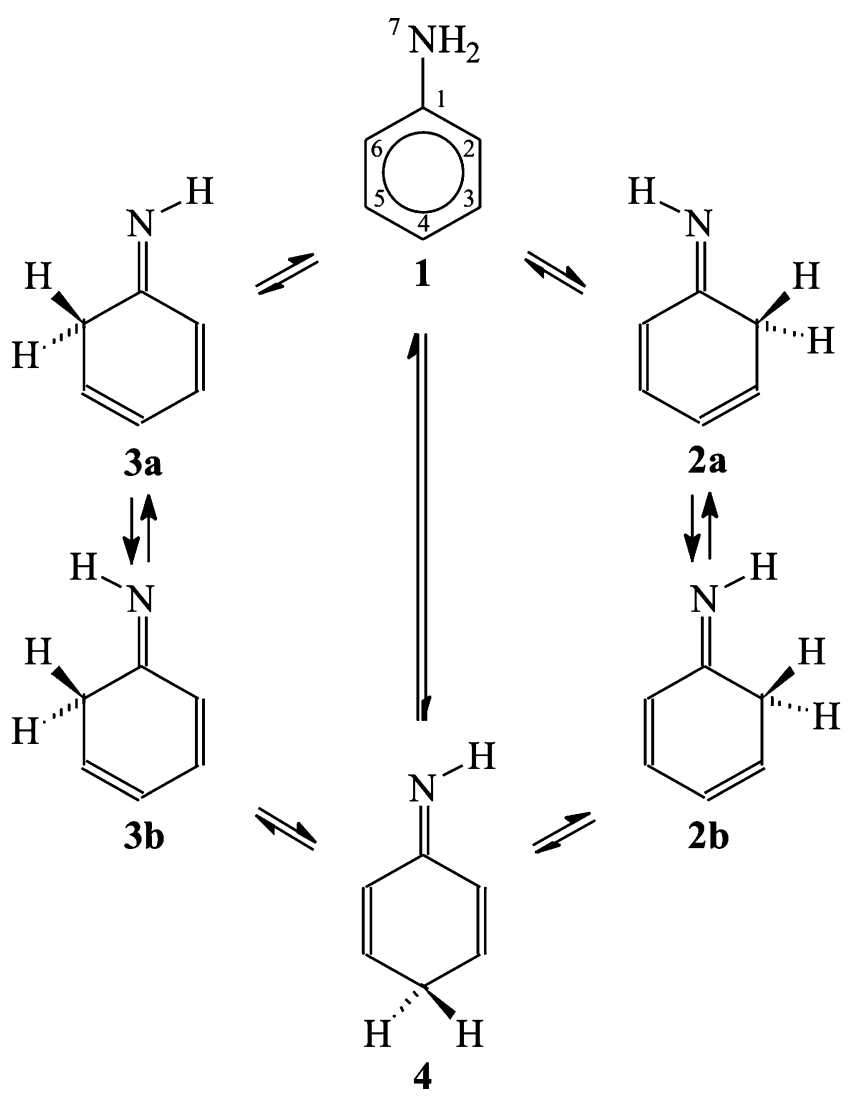

Scheme 1 Prototropic equilibria for aniline

$\left\{\right.$ e.g., $\mathrm{K}\left(\mathrm{NH}_{3}\right) \rightarrow \mathrm{K}^{+}\left(\mathrm{NH}_{3}\right)+\mathrm{e}\left(\mathrm{NH}_{3}\right)$ \} [7-14]. They may be identified by various spectroscopic techniques, e.g., zero kinetic energy photoelectron spectroscopy $[15,16]$, or infrared depletion spectroscopy [17-19]. The charged radicals may be also generated in various types of mass spectrometers during positive $\left(\mathrm{M}-\mathrm{e} \rightarrow \mathrm{M}^{+\bullet}\right)$ or negative $\left(\mathrm{M}+\mathrm{e} \rightarrow \mathrm{M}^{-*}\right)$ ionization (M - whole molecule) [20]. In such conditions, an electron may be transferred from or to aniline and change stabilities of the enamine and imine tautomers. Consequently, they may change prototropic equilibria, composition of the tautomeric mixture, and mechanisms of ion-radical reactions.

However, the redox imine forms of aniline have been usually omitted in the literature. For example, the imine radical cations and the imine radical anions have not been considered as intermediates in various mechanisms of aromatic substitution for aniline derivatives. In these reactions, solely the enamine forms, the radical cation and the radical anion, have been taken into account [21-24]. Similarly, the electronic structures, vibrational spectra, and infrared and Raman intensities have been studied by quantum-chemical methods only for the enamine tautomer of the aniline radical cation $[15,25]$. The imine isomers have not been considered.

Investigation of the distonic radical cation isomers of ionized aniline, ${ }^{\bullet} \mathrm{C}_{6} \mathrm{H}_{4}-\mathrm{NH}_{3}{ }^{+}$, is a particular case in which the enamine and imine radical cation isomers have been taken into account [26]. The distonic radical cation is a very stable reactive intermediate in the gas phase with a spatial separated radical and charge site. It can be formed during collisional activation in mass spectrometer from 2-, 3-, or 4iodoanilinium ion, $\mathrm{I}_{-} \mathrm{C}_{6} \mathrm{H}_{4}-\mathrm{NH}_{3}{ }^{+} \rightarrow \cdot{ }^{-} \mathrm{C}_{6} \mathrm{H}_{4}-\mathrm{NH}_{3}{ }^{+}$[26-28]. Although the DFT relative energies of various distonic radical cation isomers are close to those for the imine radical cation isomers and considerably larger than that of the enamine radical cation isomer [26], izomerization has not been detected by mass spectrometry [26-28]. It has been suggested that the $\cdot \mathrm{C}_{6} \mathrm{H}_{4}-\mathrm{NH}_{3}{ }^{+}$radical cation, generated by a protonation-deiodination sequence on iodoanilines, is protected against $\mathrm{H} \cdot$ shifts rearrangements to the conventional aniline radical cation, $\mathrm{C}_{6} \mathrm{H}_{5} \mathrm{NH}_{2}{ }^{+\bullet}$, by large energy barriers [26].

For our investigations on prototropy of neutral and redox forms of aniline, we chose quantum-chemical methods, because experimental techniques are incapable of detecting less than $0.1 \%$ of minor tautomer(s). We applied the DFT method [29] with the B3LYP functional [30, 31]. The DFT method has been successfully applied for proton-transfer reactions, including tautomeric conversions in the gas phase that models apolar environment [32-36]. For B3LYP calculations, the $6-311+\mathrm{G}(\mathrm{d}, \mathrm{p})$ basis set [37] with the diffuse and polarization functions was employed. For selected structures, the G2 theory [38, 39], recommended for the proton-transfer reactions [40, 41], was also applied. The G2 theory corresponds effectively to QCISD(T)/6$311+\mathrm{G}(3 \mathrm{df}, 2 \mathrm{p}) / / \mathrm{MP} 2 / 6-31 \mathrm{G}(\mathrm{d})$ calculations with zeropoint vibrational and 'higher level' corrections [38, 39]. The extended basis sets, 6-311++G(3df,3pd) and aug-ccpVDZ [37, 42], were additionally tested for DFT calculations. Since prototropy is always accompanied by $\pi$ electron transfer(s), we analysed $\pi$ - and n-electron delocalization for the neutral and redox isomers of aniline optimized at the B3LYP/6-311+G(d,p) level.

\section{Computational details}

Geometries of neutral isomers of aniline (1-4), and its oxidized and reduced forms (radical cations and anions, respectively) were fully optimized without symmetry constraints using the DFT(B3LYP) method [29-31] and the $6-311+G(d, p)$ basis set [37]. The real minima (with all positive frequencies) were found for each isomer, and thermodynamic parameters calculated using the same level of theory. For selected isomers, additional calculations were performed using the G2 theory [38, 39], and also the extended basis sets, 6-311++G(3df,3pd) and aug-cc-pVDZ $[37,42]$, for the DFT(B3LYP) method. For all calculations, the Gaussian 03 program [43] was employed. 


\section{Results and discussion}

Choice of quantum-chemical method

For two isomers (1 and $\mathbf{4}$ ) of neutral aniline, calculations were performed at various levels of theory: B3LYP/6-311+ G(d,p), B3LYP/6-311++G(3df,3pd), B3LYP/aug-cc-pVDZ, and $\mathrm{G} 2$. The calculated $\mathrm{CC}$ and $\mathrm{CN}$ bond lengths and the relative Gibbs energies $(\Delta G)$ are compared in Table 1 . The comparison shows that the B3LYP/6-311+G(d,p) level, frequently employed for the proton-transfer reactions in the gas phase, is sufficient for the tautomeric system for which the relative Gibbs energies are very different from zero. The use of different basis sets for DFT calculations has no important influence on the values of geometric and energetic parameters. The DFT relative Gibbs energies are close to those computed using the G2 theory. Differences in bond lengths are not larger than $0.01 \AA$ and differences in relative energies are not larger than $3 \mathrm{kcal} \mathrm{mol}^{-1}$. The DFT $\Delta G$ values only slightly overestimate (by ca. $10 \%$ ) those estimated by the $\mathrm{G} 2$ theory. The $\mathrm{CC}$ and $\mathrm{CN}$ bond lengths calculated for the neutral enamine isomer $\mathbf{1}$ are close to the literature experimental gas-phase microwave bond lengths [44]. They are also in good agreement with those calculated by Michalska and co-workers at the B3LYP/6-311++G(df,pd) and MP2/6-311++G(df,pd) levels [25]. There is no literature

Table 1 Comparison of the $\mathrm{CC}$ and $\mathrm{CN}$ bond lengths (in $\AA$ ) and relative energies $\left(\Delta G\right.$ in $\left.\mathrm{kcal} \mathrm{mol}^{-1}\right)$ for $\mathbf{1}$ and $\mathbf{4}$ of neutral aniline

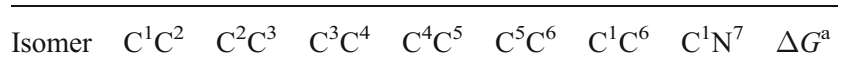

\begin{tabular}{|c|c|c|c|c|c|c|c|c|}
\hline \multicolumn{9}{|c|}{ a) B3LYP/6-311+G(d,p) } \\
\hline 1 & 1.40 & 1.39 & 1.39 & 1.40 & 1.39 & 1.40 & 1.40 & 0.0 \\
\hline 4 & 1.47 & 1.34 & 1.50 & 1.50 & 1.34 & 1.47 & 1.29 & 26.5 \\
\hline \multicolumn{9}{|c|}{ b) B3LYP/6-311++G(3df,3pd) } \\
\hline $1^{\mathrm{b}}$ & 1.40 & 1.39 & 1.39 & 1.39 & 1.39 & 1.40 & 1.40 & 0.0 \\
\hline 4 & 1.47 & 1.33 & 1.49 & 1.49 & 1.33 & 1.47 & 1.28 & 26.7 \\
\hline \multicolumn{9}{|c|}{ c) B3LYP/aug-cc-pVDZ } \\
\hline 1 & 1.41 & 1.40 & 1.40 & 1.40 & 1.40 & 1.41 & 1.40 & 0.0 \\
\hline 4 & 1.48 & 1.34 & 1.50 & 1.50 & 1.34 & 1.47 & 1.29 & 26.3 \\
\hline \multicolumn{9}{|c|}{ d) G2 \{with MP2/6-31G(d) geometry\} } \\
\hline $1^{\mathrm{c}}$ & 1.40 & 1.39 & 1.39 & 1.39 & 1.39 & 1.40 & 1.40 & 0.0 \\
\hline 4 & 1.47 & 1.34 & 1.50 & 1.50 & 1.34 & 1.46 & 1.30 & $23.9^{\mathrm{d}}$ \\
\hline \multicolumn{9}{|c|}{ f) experiment ${ }^{e}$} \\
\hline 1 & 1.40 & 1.39 & 1.40 & 1.40 & 1.39 & 1.40 & 1.40 & - \\
\hline \multicolumn{9}{|c|}{ a $\Delta G=G(\mathbf{4})-G(\mathbf{1})$} \\
\hline \multicolumn{9}{|c|}{ b The same CC and CN bond lengths as in ref. [25] } \\
\hline \multicolumn{9}{|c|}{$\begin{array}{l}\text { The same } \mathrm{CC} \text { and } \mathrm{CN} \text { bond lengths at the MP2/6-311++G(df,pd) level } \\
\text { were reported in ref. [25] }\end{array}$} \\
\hline \multicolumn{9}{|c|}{$\begin{array}{l}\text { d The following } \Delta G \text { values were found at the } \mathrm{G} 1 \text { and G2(MP2) levels: } \\
24.1 \text { and } 23.8 \mathrm{kcal} \mathrm{mol}^{-1} \text {, respectively }\end{array}$} \\
\hline
\end{tabular}

data for the neutral imine isomer $\mathbf{4}$ and no comparison can be made.

Delocalization of $n$ - and $\pi$-electrons

First perusal of the bond lengths calculated at the B3LYP/6$311+\mathrm{G}(\mathrm{d}, \mathrm{p})$ level for the neutral and charged radicals of $\mathbf{1}$ shows that addition of one electron to aromatic system does not alter the geometric parameters significantly (Table 2). The CC bond lengths for the radical anion (1.39-1.41 $\AA$ ) are close to those for the neutral form (1.39-1.40 $\AA$ ), and the $\mathrm{CN}$ bond length for the radical anion $(1.40 \AA)$ is the same as that for the neutral molecule (1.40 $\AA$ ). Important differences take place for the radical cation. Loss of one electron shortens the $\mathrm{CN}$ bond $(1.33 \AA$ ) in comparison to the neutral molecule. It also differentiates the $\mathrm{CC}$ bond lengths, which vary from 1.37 to $1.43 \AA$, indicating some kind of $\pi$ electron localization. For the imine tautomers $\mathbf{2 - 4}$, oneelectron oxidation and one-electron reduction seem to have only slight effect on some $\mathrm{CC}$ bond lengths. For the neutral forms, they vary from 1.34 to $1.53 \AA$, and for the charged forms, they vary from 1.35 to $1.54 \AA$. Moreover, the $\mathrm{CN}$ bonds are slightly longer for the charged radicals (1.30-1.35 $\AA$ ) than for the neutral forms (1.28-1.29 $\AA$ ).

To quantitatively measure $\pi$-electron delocalization for all isomers of aniline, the geometry-based HOMED index $[45,46]$ can be applied. This index describes well various types of conjugations $(\pi-\pi, n-\pi$, and $\sigma-\pi)$ possible in systems containing heteroatoms [46]. The HOMED index can be obtained from the theoretically derived bond lengths [B3LYP/6-311+G(d,p)] using Eq. 1. In this equation, $\alpha$ is a normalization constant, $\mathrm{R}_{\mathrm{o}}$ is the optimum bond length

Table 2 The DFT calculated CC and CN bond lengths (in $\AA$ ) for isomers of aniline

\begin{tabular}{lccccccc}
\hline $\begin{array}{l}\text { Isomer } \\
\text { a) neutral }\end{array}$ & $\mathrm{C}^{1} \mathrm{C}^{2}$ & $\mathrm{C}^{2} \mathrm{C}^{3}$ & $\mathrm{C}^{3} \mathrm{C}^{4}$ & $\mathrm{C}^{4} \mathrm{C}^{5}$ & $\mathrm{C}^{5} \mathrm{C}^{6}$ & $\mathrm{C}^{1} \mathrm{C}^{6}$ & $\mathrm{C}^{1} \mathrm{~N}^{7}$ \\
$\mathbf{1}$ & 1.40 & 1.39 & 1.39 & 1.40 & 1.39 & 1.40 & 1.40 \\
$\mathbf{2} \mathrm{a} / \mathbf{3 a}$ & 1.52 & 1.50 & 1.34 & 1.46 & 1.35 & 1.47 & 1.28 \\
$\mathbf{2 b} / \mathbf{3 b}$ & 1.53 & 1.50 & 1.34 & 1.46 & 1.35 & 1.46 & 1.28 \\
$\mathbf{4}$ & 1.47 & 1.34 & 1.50 & 1.50 & 1.34 & 1.47 & 1.29 \\
$\mathbf{b} \mathbf{2}$ radical cation & & & & & & \\
$\mathbf{1}$ & 1.43 & 1.37 & 1.41 & 1.41 & 1.37 & 1.43 & 1.33 \\
$\mathbf{2 a} / \mathbf{3 a}$ & 1.50 & 1.47 & 1.38 & 1.41 & 1.39 & 1.44 & 1.30 \\
$\mathbf{2 b} / \mathbf{3 b}$ & 1.51 & 1.48 & 1.38 & 1.41 & 1.39 & 1.44 & 1.30 \\
$\mathbf{4}$ & 1.44 & 1.35 & 1.48 & 1.48 & 1.35 & 1.44 & 1.32 \\
$\mathbf{c} \mathbf{~ r a d i c a l ~ a n i o n ~}$ & & & & & & \\
$\mathbf{1}$ & 1.41 & 1.39 & 1.40 & 1.40 & 1.39 & 1.41 & 1.40 \\
$\mathbf{2 a} / \mathbf{3 a}$ & 1.53 & 1.51 & 1.38 & 1.42 & 1.41 & 1.42 & 1.32 \\
$\mathbf{2 b} / \mathbf{3 b}$ & 1.54 & 1.51 & 1.38 & 1.42 & 1.40 & 1.42 & 1.32 \\
$\mathbf{4}$ & 1.44 & 1.37 & 1.51 & 1.51 & 1.36 & 1.45 & 1.35 \\
\hline
\end{tabular}


(assumed to be realized when full delocalization of $\pi$ electrons takes place), $R_{i}$ are the running bond lengths in the system, and $\mathrm{n}$ is the number of bonds taken into account.

HOMED $=1-\left[\alpha \cdot \Sigma\left(R_{o}-R_{i}\right)^{2}\right] / n$

For the system containing the even number of bonds $(n=2 i)$, i.e., the same number of single (i) and double (i) bonds, the normalization $\alpha$ constant can be calculated from Eq. 2 proposed for the HOMA index [47], where $R_{s}$ and $R_{d}$ are the single and double bond lengths of the reference compounds [46]. For the system containing the odd number of bonds $(n=2 i+1)$, i.e., $(i+1)$ single bonds and (i) double bonds, the normalization $\alpha$ constant can be calculated from Eq. 3 [46]. The following $R_{s}, R_{d}$, and $R_{o}$ values (in $\AA$ ), calculated at the B3LYP/6-311+G(d,p) level [46] were taken here: 1.5300 (ethane), 1.3288 (ethene) and 1.3943 (benzene) for the CC bonds, and 1.4658 (methylamine), 1.2670 (methylimine) and 1.3342 (1,3,5-triazine) for the $\mathrm{CN}$ bonds. On the basis of these $\mathrm{R}$ values, the normalization $\alpha$ constant equal to 88.09 was used for the ring (six C-atoms). For the whole tautomeric system (seven atoms, one $\mathrm{N}$-atom and six C-atoms), the following $\alpha$ constants were applied: 80.90 for the $\mathrm{CC}$ bonds and 84.52 for the $\mathrm{CN}$ bonds.

$\alpha_{2 i}=2 \cdot\left[\left(R_{o}-R_{S}\right)^{2}+\left(R_{o}-R_{d}\right)^{2}\right]^{-1}$

$\alpha_{2 i+1}=(2 i+1) \cdot\left[(i+1) \cdot\left(R_{o}-R_{S}\right)^{2}+i \cdot\left(R_{o}-R_{d}\right)^{2}\right]^{-1}$

The HOMED indices (Table 3) calculated for the ring are close to unity for the neutral enamine tautomer $1(0.9976)$ and for its radical anion (0.9944). For the radical cation of $\mathbf{1}$, the HOMED index is slightly lower (0.9265). Presence of the $\mathrm{C}-\mathrm{sp}^{3}$ atom in the ring for the imine tautomers (2-4) destroys aromatic character of the ring, and decreases the

Table 3 The DFT estimated HOMED indices for isomers of aniline

\begin{tabular}{llll}
\hline Isomer & Neutral form & Radical cation & Radical anion \\
\hline
\end{tabular}

a) for the ring (six C-atoms)

$\begin{array}{llll}\mathbf{1} & 0.9976 & 0.9265 & 0.9944 \\ \mathbf{2} \mathrm{a} / \mathbf{3 a} & 0.3844 & 0.7109 & 0.4904 \\ \mathbf{2 b} / \mathbf{3 b} & 0.3533 & 0.6698 & 0.4704 \\ \mathbf{4} & 0.4130 & 0.6802 & 0.5135\end{array}$

b) for the whole tautomeric system (seven atoms, one $\mathrm{N}$-atom and six C-atoms)

\begin{tabular}{llll}
$\mathbf{1}$ & 0.9479 & 0.9422 & 0.9520 \\
$\mathbf{2} \mathrm{a} / \mathbf{3 a}$ & 0.4825 & 0.7598 & 0.5973 \\
$\mathbf{2 b} / \mathbf{3 b}$ & 0.4591 & 0.7248 & 0.5820 \\
$\mathbf{4}$ & 0.5106 & 0.7471 & 0.5949 \\
\hline
\end{tabular}

HOMED indices in higher degree for the neutral (0.35-0.41) than for the charged radicals, anions (0.47-0.51) and cations (0.67-0.71). When proceeding from the ring (six C-atoms) to the whole tautomeric system (seven atoms), the HOMED indices decrease for the neutral enamine tautomer $\mathbf{1}$ (from 0.9976 to 0.9479 ) and for its radical anion (from 0.9944 to 0.9520 ) due to cross $n-\pi$ and $\pi-\pi$ conjugations possible in the whole tautomeric system, i.e., conjugation of n-electrons of the $\mathrm{NH}_{2}$ group with $\pi$-electrons of the ring. Exception is the enamine radical cation, for which conjugation of the positive charge with $\pi$ - or n-electrons increases the number of resonance structures, and consequently, increases the $\pi$ electron delocalization and the HOMED index (from 0.9265 to 0.9422 ). For the imine forms $\mathbf{2 - 4}$, the HOMED indices increase. This increase may be explained by additional $\pi-\pi$ cross conjugation of the exo-C $=\mathrm{NH}$ group with $\pi$-electrons of the ring. The $\pi-\pi$ conjugation leads usually to greater $\pi$ electron delocalization than $\sigma-\pi$ hyperconjugation possible in the ring for the $-\mathrm{CH}=\mathrm{CH}-\mathrm{CH}_{2}-$ group(s).

\section{Relative stabilities}

For all isomers, the DFT minima (with real frequencies) were found and the thermodynamic parameters such as the energy $(E)$, enthalpy $(H)$, entropy $(S)$, and Gibbs (free) energy ( $G$ for $T=298.15 \mathrm{~K}$ ) were calculated. The $G$ value includes the electronic energy, the zero-point energy (ZPE), and the thermal corrections (vibrational, rotational, and translational) to the energy and entropy. For the enamineimine conversions, the relative energies $\left(\Delta E_{\mathrm{T}}\right)$, enthalpies

Table 4 The DFT calculated thermodynamic parameters $\left(\Delta E_{\mathrm{T}}, \Delta H_{\mathrm{T}}\right.$, $T \Delta S_{\mathrm{T}}$, and $\Delta G_{\mathrm{T}}$ in kcal mol${ }^{-1}$ ) for the enamine-imine conversions in aniline and the percentage contents ( $x$ in \%) of the imine tautomers

\begin{tabular}{|c|c|c|c|c|c|}
\hline Conversion & $\Delta E_{\mathrm{T}}^{\mathrm{a}, \mathrm{b}}$ & $\Delta H_{\mathrm{T}}^{\mathrm{b}, \mathrm{c}}$ & $T \Delta S_{\mathrm{T}}^{\mathrm{b}, \mathrm{c}}$ & $\Delta G_{\mathrm{T}}^{\mathrm{b}, \mathrm{c}}$ & $\mathrm{x}$ \\
\hline \multicolumn{6}{|c|}{ a) neutral form } \\
\hline $1 \rightarrow 2 \mathrm{a} / 3 \mathrm{a}$ & 28.7 & 28.8 & 0.6 & 28.2 & $1 \cdot 10^{-19}$ \\
\hline $1 \rightarrow 2 \mathrm{~b} / 3 \mathrm{~b}$ & 29.0 & 29.1 & 0.7 & 28.4 & $1 \cdot 10^{-19}$ \\
\hline $1 \rightarrow 4$ & 26.6 & 26.6 & 0.2 & 26.5 & $4 \cdot 10^{-18}$ \\
\hline \multicolumn{6}{|c|}{ b) radical cation } \\
\hline $1 \rightarrow 2 \mathrm{a} / 3 \mathrm{a}$ & 43.5 & 43.8 & 0.7 & 43.1 & $1 \cdot 10^{-30}$ \\
\hline $1 \rightarrow 2 \mathrm{~b} / 3 \mathrm{~b}$ & 43.4 & 43.6 & 0.7 & 43.0 & $1 \cdot 10^{-30}$ \\
\hline $1 \rightarrow 4$ & 48.2 & 48.5 & 0.6 & 47.9 & $8 \cdot 10^{-34}$ \\
\hline \multicolumn{6}{|c|}{ c) radical anion } \\
\hline $1 \rightarrow 2 \mathrm{a} / 3 \mathrm{a}$ & -3.9 & -3.6 & 1.0 & -4.7 & 89.0 \\
\hline $1 \rightarrow 2 \mathrm{~b} / 3 \mathrm{~b}$ & -2.9 & -2.7 & 0.8 & -3.4 & 11.0 \\
\hline $1 \rightarrow 4$ & 4.9 & 5.1 & 0.5 & 4.6 & $1.4 \cdot 10^{-5}$ \\
\hline
\end{tabular}

a $\mathrm{ZPE}$ included. At $0 \mathrm{~K}$

b $\Delta Q_{\mathrm{T}}=Q(\mathbf{i})-Q(\mathbf{1}), Q=E, H, S$, or $G$

c Thermal corrections included. At $298.15 \mathrm{~K}$ 
$\left(\Delta H_{\mathrm{T}}\right)$, entropy therms $\left(T \Delta S_{\mathrm{T}}\right)$, Gibbs energies $\left(\Delta G_{\mathrm{T}}\right)$, and also the percentage contents $(x)$ of the imine tautomers were calculated on the basis of Eq. 4, where $K_{\mathrm{T}}$ is the tautomeric equilibrium constant. They are given in Table 4 .

$-\log [x /(100-x)]=p K_{T}=\Delta G_{T} / 2.302 R T$

According to DFT calculations, the enamine tautomer (1) has the lowest $G$ value for the neutral molecule. This form is the most stable one in the gas-phase as well as in solution [1$6,44]$. The percentage contents of the imine tautomers (2-4) in the tautomeric mixture are exceptionally small $\left(<10^{-15} \%\right)$, and from a physicochemical point of view they may be neglected. For the simplest acyclic enamine-imine tautomeric system, the E-isomer of acetaldimine $\left(\mathrm{CH}_{3}-\mathrm{CH}=\mathrm{NH}\right)$ is more stable than vinylamine $\left(\mathrm{CH}_{2}=\mathrm{CH}-\mathrm{NH}_{2}\right)$ with energy difference of $4 \mathrm{kcal} \mathrm{mol}^{-1}$ at the $\mathrm{G} 2$ level [48]. The Z-isomer of acetaldimine is also more stable than vinylamine, but it has larger energy than the E-isomer by $1 \mathrm{kcal} \mathrm{mol}^{-1}$ at the MP4/6$311++\mathrm{G}(\mathrm{d}, \mathrm{p}) / / \mathrm{MP} 2 / 6-31 \mathrm{G}(\mathrm{d})$ level (ZPVE included) [48]. The tautomeric preference for aliphatic derivative is not the same as that for aromatic system for which a part of the tautomeric moiety, the $\mathrm{NH}_{2}$ group, is not included in the ring according to the exo-mode. This change of the tautomeric preference when proceeding from aliphatic to aromatic system may be explained by the energies describing aromatic stability, e.g., resonance energy (RE 30-50 $\mathrm{kcal} \mathrm{mol}^{-1}$ ) for simple aromatics $[3,4,49,50]$, which are considerably larger than the tautomeric energy for the parent system.
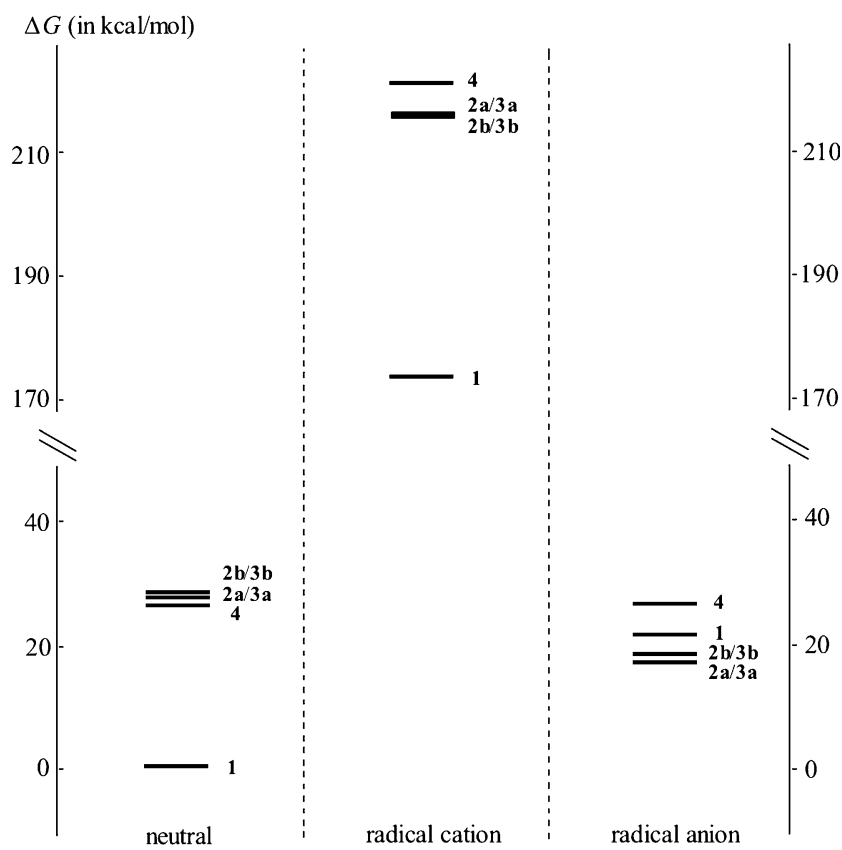

Fig. 1 The DFT relative Gibbs energies $(\Delta G)$ for isomers of neutral and charged aniline

Table 5 The DFT calculated thermodynamic parameters (in kcal mol ${ }^{-1}$ ) for oxidation and reduction reactions of individual isomers of aniline

\begin{tabular}{lllll}
\hline Isomer & $\Delta E^{\mathrm{a}, \mathrm{b}}$ & $\Delta H^{\mathrm{b}, \mathrm{c}}$ & $T \Delta S^{\mathrm{b}, \mathrm{c}}$ & $\Delta G^{\mathrm{b}, \mathrm{c}}$ \\
\hline a) oxidation & & & & \\
$\mathbf{1}$ & 174.1 & 174.0 & 0.3 & 173.7 \\
$\mathbf{2 a} / \mathbf{3 a}$ & 188.9 & 189.0 & 0.4 & 188.7 \\
$\mathbf{2 b} / \mathbf{3 b}$ & 188.5 & 188.6 & 0.3 & 188.3 \\
$\mathbf{4}$ & 195.7 & 196.0 & 0.8 & 195.2 \\
b) reduction & & & & \\
$\mathbf{1}$ & 22.2 & 22.2 & 0.4 & 21.8 \\
$\mathbf{2 a} / \mathbf{3 a}$ & -10.4 & -10.2 & 0.9 & -11.0 \\
$\mathbf{2 b} / \mathbf{3 b}$ & -9.7 & -9.6 & 0.5 & -10.0 \\
$\mathbf{4}$ & 0.5 & 0.7 & 0.7 & 0.0 \\
\hline
\end{tabular}

${ }^{a}$ ZPE included. At $0 \mathrm{~K}$

b $\Delta Q_{\mathrm{T}}=Q($ charged form $)-Q$ (neutral form), $Q=E, H, S$, or $G$; the charged form is the radical cation for oxidation and the radical anion for reduction

c Thermal corrections included. At $298.15 \mathrm{~K}$

One-electron oxidation has no effect on the tautomeric preference for aniline. The enamine tautomer (1) predominates in the tautomeric mixture. It has the lowest energy [26]. One-electron oxidation influences solely the relative energies, and consequently, the amounts of the imine isomers. The $\Delta G_{\mathrm{T}}$ values for the imine radical cation isomers are ca. one and a half larger than those for the neutral forms, and the percentage contents of the imine isomers are not larger than $10^{-30} \%$. Change of the $\mathrm{H}$ atom configuration at the $\mathrm{N}$ atom when going from $\mathbf{2 a} / \mathbf{3} \mathbf{a}$ to $\mathbf{2 b} / \mathbf{3 b}$ has no important effect on the relative stabilities $(<0.3 \mathrm{kcal}$ $\mathrm{mol}^{-1}$ ) of the neutral and oxidized forms. This effect has not been discussed by Nguen and co-workers [26]. However, similar relative energies $\{\mathrm{B} 3 \mathrm{LYP} / 6-311++\mathrm{G}(\mathrm{d}, \mathrm{p})+\mathrm{ZPE}\}$ between the enamine and imine tautomers have been reported. The orders of stabilities are as follows: $1>\mathbf{4}>\mathbf{2 a} /$ $\mathbf{3 a} \approx \mathbf{2} b / \mathbf{3 b}$ for the neutral molecule and $\mathbf{1}>\mathbf{2 b} / \mathbf{3} b \approx \mathbf{2 a} / \mathbf{3 a}>\mathbf{4}$ for oxidized aniline. For the oxidized aliphatic parent system, the order of stabilities is reversed in comparison to that for the neutral molecule [51]. The vinylamine radical cation is considerably more stable than the acetaldimine radical cation by $29 \mathrm{kcal} \mathrm{mol}^{-1}$ at the G2(MP2) level [51], indicating that enamine-imine isomerization is endothermic for the oxidized acyclic system, similarly as for oxidized aniline.

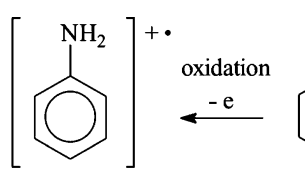

$\Delta G\left(\mathrm{kcal} \mathrm{mol}^{-1}\right)$

HOMED 0.9422

Scheme 2 The tautomeric preference and $\pi$-electron delocalization for redox forms of aniline estimated at the B3LYP/6-311+G(d,p) level 
An interesting change of the tautomeric preference occurs for reduced aniline. One-electron reduction favors the imine isomer $\mathbf{2 a / 3} \mathbf{a}$. The other imine radical anion isomers $\mathbf{2 b} / \mathbf{3 b}$ and $\mathbf{4}$ have larger $G$ values than $\mathbf{2 a} / \mathbf{3 a}$. The

a inductive effect

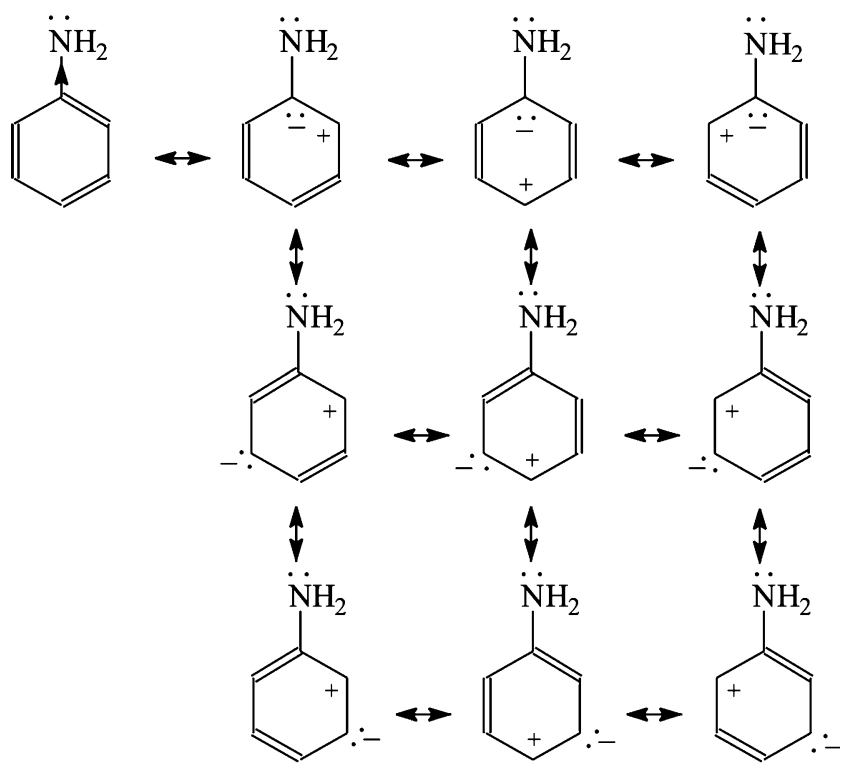

b resonance effect<smiles>Nc1ccccc1</smiles><smiles>Cc1ccccc1</smiles><smiles>[NH2+]=C1[C-]C=CC=C1</smiles><smiles>[NH2+]=C1C=CCC=C1</smiles><smiles>C=C1C=CC=CC1=[NH2+]</smiles><smiles>[CH][TeH]</smiles><smiles>Nc1[c-]cccc1</smiles><smiles>[14CH3][As]</smiles><smiles>[NH2+]</smiles><smiles>Nc1ccccc1I</smiles><smiles>C1C[Te]C[As]1</smiles><smiles>CC=Cc1ccccc1N</smiles><smiles>[3H][Mg]</smiles><smiles>Nc1ccccc1I</smiles><smiles>NNc1ccccc1-c1ccccc1N</smiles><smiles>Nc1ccccc1I</smiles>

Scheme 3 Electronic effects of the exo- $\mathrm{NH}_{2}$ group for the neutral enamine isomer 1 enamine radical anion isomer $\mathbf{1}$ also has larger $G$ value. The tautomeric mixture of reduced aniline consists mainly of the imine isomers $\mathbf{2 a / 3} \mathbf{a}(89 \%)$ and $\mathbf{2 b} / \mathbf{3 b}(11 \%)$. These isomers have to be considered for all electron transfer reactions for which aniline gains one electron. The percentage contents of other tautomers are lower than $0.05 \%$. The order of stabilities for the reduced forms of aniline $(\mathbf{2 a} / \mathbf{3} \mathbf{a} \approx \mathbf{2} \mathbf{b} / \mathbf{3} \mathbf{b}>\mathbf{4}>\mathbf{1})$ is completely reversed to that $(\mathbf{1}>\mathbf{4}>\mathbf{2} a / \mathbf{3} a \approx \mathbf{2} b / \mathbf{3 b})$ for the neutral molecule. Change of the $\mathrm{H}$ configuration at the $\mathrm{N}$ atom when going from $\mathbf{2 a} / \mathbf{3 a}$ to $\mathbf{2 b} / \mathbf{3 b}$ has only a slight effect on the relative stabilities $\left(1.3 \mathrm{kcal} \mathrm{mol}^{-1}\right)$. There are no reports on reduced aniline, so

\section{a isomer 2}

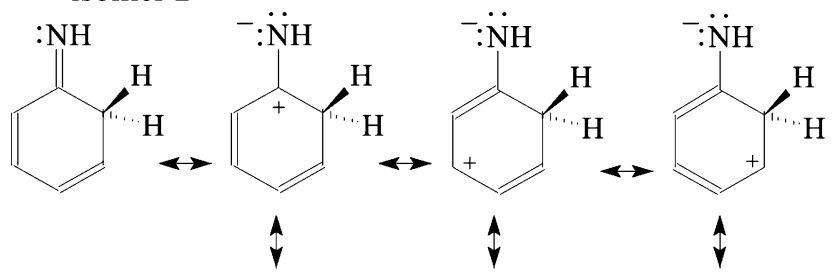

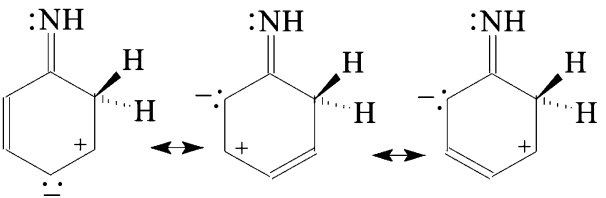

b isomer 3<smiles>CC1=CC(=N)CC=C1</smiles>

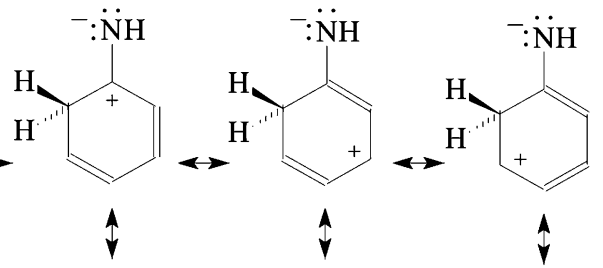

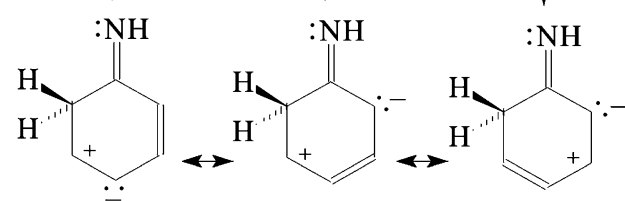

C isomer 4

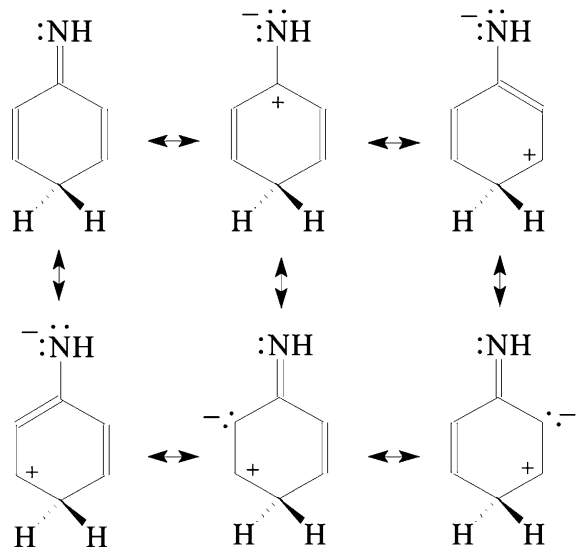

Scheme 4 Electronic effects of the exo $=\mathrm{NH}$ group for the neutral imine isomers 2-4 
no comparison can be made. For the reduced aliphatic parent system, the order of stabilities is the same as for the neutral molecule. The acetaldimine radical anion is more stable than the vinylamine radical anion by $1 \mathrm{kcal} \mathrm{mol}^{-1}$ at the B3LYP/6$311+\mathrm{G}(\mathrm{d}, \mathrm{p})$ level. One-electron reduction stabilizes the imine tautomer for the parent system similarly as for aniline.

The relative entropy terms $\left(T \Delta S_{\mathrm{T}}\right)$ for the reduced forms of aniline are not larger than $\pm 1 \mathrm{kcal} \mathrm{mol}^{-1}$, similarly as for the neutral and oxidized molecule. This suggests that tautomeric enamine-imine conversions are isoentropic in the gas phase and do not depend on the oxidation or reduction state of aniline. Generally, there are not large structural changes during tautomerization. Some exceptions are those resulting from loss of the ring planarity for the imine tautomers.

Oxidation and reduction energies

When oxidizing agents are present, the neutral aniline may lose one electron. Consequently, it may be transferred to its oxidized (ionized) very reactive state $\left(\mathrm{PhNH}_{2}-\mathrm{e} \rightarrow\right.$ $\left.\left[\mathrm{PhNH}_{2}\right]^{+\bullet}\right)$. The mechanisms of chemical and anodic oxidations of aniline and formation of polymeric products are very complex and depend on conditions of reaction such as solvent, reagents, catalysts, etc. (see for example refs. [814, 52-59]). These processes may pass through different intermediates among which the radical cation of aniline $\left(\mathrm{PhNH}_{2}^{+*}\right)$ is possible [8-14, 52-57]. Oxidation of aniline by oxygen from air, catalyzed by sunlight or UV light, is also a very complex process [13, 60-62]. It may occur even in a closed bottle of aniline when colored products appear. A simple loss of one electron may also be observed for aniline during positive ionization in the mass spectrometer, when the molecular ion $\left(\mathrm{PhNH}_{2}{ }^{+\bullet}\right)$ is generated [20].

The relative Gibbs energies calculated at the B3LYP/6$311+G(d, p)$ level for the neutral, oxidized and reduced enamine and imine tautomers of aniline are compared in Fig. 1, where the $\Delta G$ values are relative to the $G$ value of the neutral enamine tautomer 1. The comparison indicates that one-electron oxidation process is very endothermic and
Table 6 DFT calculated Mulliken charges for isomers of aniline a $\Delta$ is the difference of the Mulliken charges on the $\mathrm{C}$ and $\mathrm{N}$ atoms between the charged and neutral form

\begin{tabular}{|c|c|c|c|c|c|c|}
\hline Isomer & Atom & Neutral form & Radical cation & $\Delta^{\mathrm{a}}$ & Radical anion & $\Delta^{\mathrm{a}}$ \\
\hline \multirow[t]{7}{*}{1} & $\mathrm{C} 1$ & -0.161 & 0.012 & 0.17 & -7.499 & -7.34 \\
\hline & $\mathrm{C} 2$ & 0.025 & 0.038 & 0.01 & 6.874 & 6.85 \\
\hline & $\mathrm{C} 3$ & -0.199 & -0.182 & 0.02 & -5.617 & -5.42 \\
\hline & $\mathrm{C} 4$ & -0.145 & -0.001 & 0.14 & 2.388 & 2.53 \\
\hline & $\mathrm{C} 5$ & -0.199 & -0.182 & 0.02 & -5.615 & -5.42 \\
\hline & $\mathrm{C} 6$ & 0.026 & 0.038 & 0.01 & 6.873 & 6.85 \\
\hline & N7 & -0.360 & -0.265 & 0.09 & 0.529 & 0.89 \\
\hline \multirow[t]{7}{*}{$2 \mathrm{a} / 3 \mathrm{a}$} & $\mathrm{C} 1$ & -0.066 & 0.025 & 0.09 & -0.326 & -0.26 \\
\hline & $\mathrm{C} 2 / \mathrm{C} 6$ & -0.484 & -0.659 & -0.18 & -0.228 & 0.26 \\
\hline & $\mathrm{C} 3 / \mathrm{C} 5$ & 0.134 & 0.290 & 0.16 & -0.098 & -0.23 \\
\hline & $\mathrm{C} 4$ & -0.219 & -0.134 & 0.08 & -0.162 & 0.06 \\
\hline & $\mathrm{C} 5 / \mathrm{C} 3$ & 0.005 & 0.005 & 0.00 & -0.198 & -0.20 \\
\hline & $\mathrm{C} 6 / \mathrm{C} 2$ & -0.167 & -0.001 & 0.16 & -0.172 & -0.01 \\
\hline & N7 & -0.293 & -0.132 & 0.16 & -0.447 & -0.15 \\
\hline \multirow[t]{7}{*}{$2 \mathrm{~b} / 3 \mathrm{~b}$} & $\mathrm{C} 1$ & 0.019 & 0.165 & 0.15 & -0.299 & -0.32 \\
\hline & $\mathrm{C} 2 / \mathrm{C} 6$ & -0.675 & -0.817 & -0.14 & -0.516 & 0.16 \\
\hline & $\mathrm{C} 3 / \mathrm{C} 5$ & 0.124 & 0.301 & 0.18 & -0.130 & -0.25 \\
\hline & $\mathrm{C} 4$ & -0.191 & -0.143 & 0.05 & -0.147 & 0.04 \\
\hline & $\mathrm{C} 5 / \mathrm{C} 3$ & -0.073 & -0.015 & 0.06 & -0.228 & -0.16 \\
\hline & $\mathrm{C} 6 / \mathrm{C} 2$ & 0.000 & 0.034 & 0.03 & 0.139 & 0.14 \\
\hline & N7 & -0.308 & -0.154 & 0.15 & -0.465 & -0.16 \\
\hline \multirow[t]{7}{*}{4} & $\mathrm{C} 1$ & -0.158 & 0.174 & 0.33 & -0.597 & -0.44 \\
\hline & $\mathrm{C} 2$ & -0.089 & -0.219 & -0.13 & 0.002 & 0.09 \\
\hline & $\mathrm{C} 3$ & 0.151 & 0.261 & 0.11 & -0.077 & -0.23 \\
\hline & $\mathrm{C} 4$ & -0.770 & -0.938 & -0.17 & -0.731 & 0.04 \\
\hline & $\mathrm{C} 5$ & 0.124 & 0.310 & 0.19 & -0.005 & -0.13 \\
\hline & C6 & -0.034 & -0.110 & -0.08 & 0.231 & 0.26 \\
\hline & N7 & -0.289 & -0.070 & 0.22 & -0.463 & -0.17 \\
\hline
\end{tabular}


requires ca. $200 \mathrm{kcal} \mathrm{mol}^{-1}$. Indeed, the experimental ionization energy for aniline is equal to $178 \mathrm{kcal} \mathrm{mol}^{-1}$ [63]. Similar results have been reported by Nguyen and co-workers [26] who calculated the adiabatic ionization energy for $\mathbf{1}$ as equal to $174\{\mathrm{~B} 3 \mathrm{LYP} / 6-311++\mathrm{G}(\mathrm{d}, \mathrm{p})\}$ and $175 \mathrm{kcal} \mathrm{mol}^{-1}$ $\{\operatorname{CCSD}(\mathrm{T}) / 6-311++\mathrm{G}(\mathrm{d}, \mathrm{p})\}$. On the other hand, one-electron gain is possible in the presence of reducing agents or during negative ionization in the mass spectrometer, where the neutral molecule is transferred to its reduced state $\left(\mathrm{PhNH}_{2}+\right.$ $\left.\mathrm{e} \rightarrow\left[\mathrm{PhNH}_{2}\right]^{-*}\right)[7,20]$. This process is less endothermic than oxidation and requires ca. $20 \mathrm{kcal} \mathrm{mol}^{-1}$. Unfortunately, there

a loss of one electron from the $\pi$-orbital of the $\mathrm{C}$ atom<smiles>Nc1ccc(CNc2ccc(CNc3ccc(CNc4ccc(N)cc4)cc3)cc2)cc1</smiles>

b loss of one electron from the n-orbital of the $\mathrm{N}$ atom

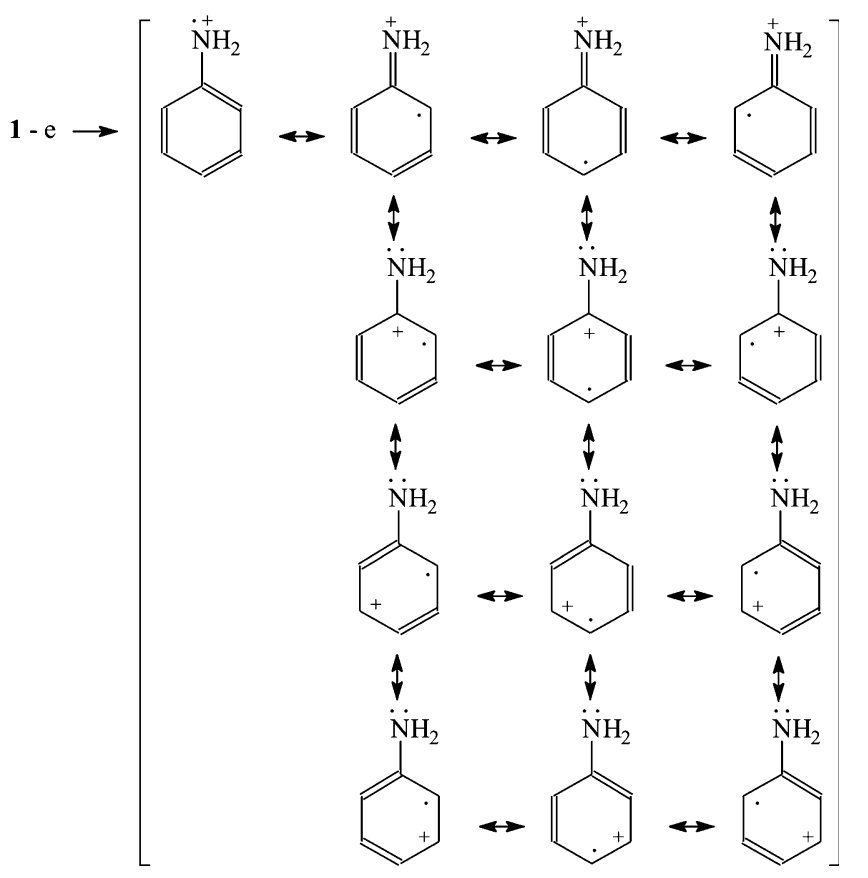

Scheme 5 Loss of one electron for enamine isomer 1, and delocalization of electrons and positive charge for its radical cation is no experimental data for the electron affinity of aniline [63] and no comparison can be made.

For each individual isomer, the thermodynamic parameters of one-electron oxidation and of one-electron reduction can be estimated as differences between the parameters of the corresponding charged radicals (cations and anions) and the neutral forms (Table 5). The $\Delta E, \Delta H$, and $\Delta G$ values for the oxidized enamine tautomer 1 are lower than those for the oxidized imine tautomers $2-4$ by ca. $20 \mathrm{kcal}$ $\mathrm{mol}^{-1}$. On the other hand, they are negative for reduced $\mathbf{2 a} /$ $\mathbf{3 a}$ and $\mathbf{2 b} / \mathbf{3 b}$, close to zero for reduced 4 , and positive for reduced $\mathbf{1}$. The variations of the oxidation and reduction parameters confirm the orders of stabilities for oxidized and reduced aniline isomers. They confirm also the change of the tautomeric preference for the reduced aniline. The entropy terms for both oxidation and reduction reactions are not larger than $1 \mathrm{kcal} \mathrm{mol}^{-1}$, indicating that the electrontransfer processes are isoentropic in the gas phase for

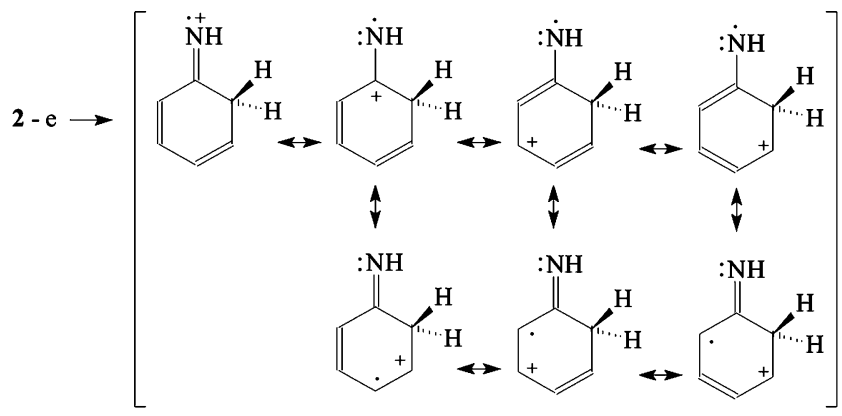

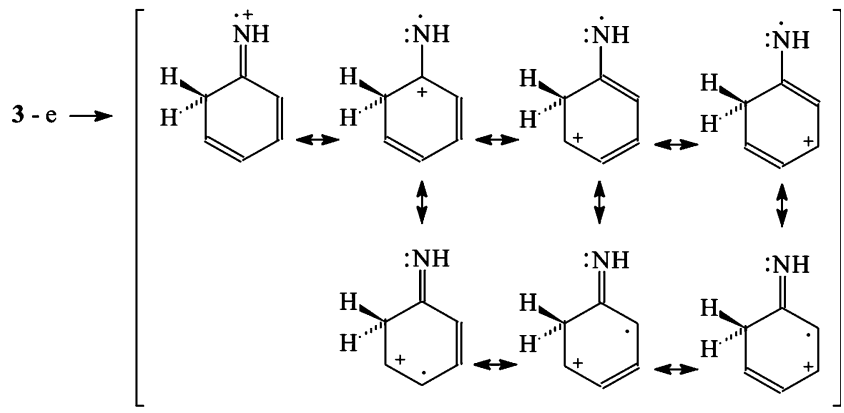

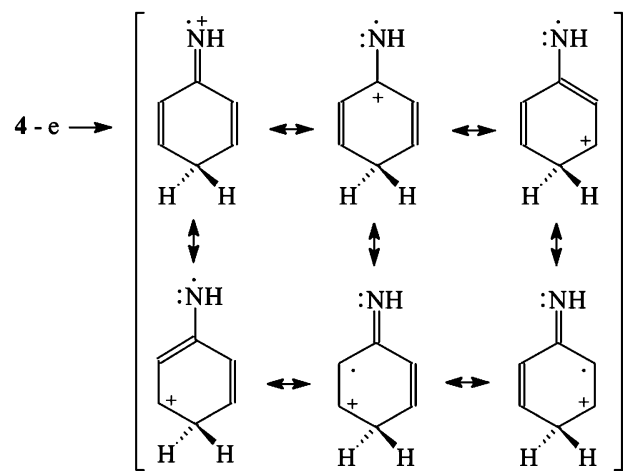

Scheme 6 Loss of one electron for the imine isomers 2-4, and delocalization of electrons and positive charge for its radical cation 
<smiles>NCNc1ccc(NCNc2cccc(N)c2)c(F)c1</smiles>

Scheme 7 Gain of one electron for aniline (1), and delocalization of electrons and negative charge for its radical anion

aniline similarly as the proton-transfer interconversions. The relative thermal corrections are also close to zero, and thus $\Delta E \approx \Delta H \approx \Delta G$.

If we consider solely the favored neutral and redox forms of aniline, i.e., the enamine isomer $\mathbf{1}$ for the neutral and oxidized form (radical cation), and the imine isomer $\mathbf{2} \mathbf{a} / \mathbf{3 a}$ for the reduced form (radical anion), the following scheme of the redox reactions can be drawn (Scheme 2). The relative Gibbs energies calculated at the B3LYP/6-311+G(d,p) level and the HOMED indices estimated for the geometries optimized at the same level of theory are also given in this scheme. The oxidation energies are close to $170 \mathrm{kcal} \mathrm{mol}^{-1}$ and the reduction energies are ten times lower $\left(17 \mathrm{kcal} \mathrm{mol}^{-1}\right)$. The variation of the tautomeric preferences and $\pi$-electron delocalization when proceeding from the neutral molecule to its redox forms may be helpful in understanding the mechanisms of various organic reactions for aniline and of biochemical transformations for aromatic biomolecules containing the $\mathrm{NH}_{2}$ group in the ring.

\section{Mulliken charges}

It is well known that for the neutral enamine isomer 1, the exo $-\mathrm{NH}_{2}$ group influences the phenyl ring by its electronic inductive and resonance effects (Scheme 3). These effects are not parallel. The inductive effect is electron-accepting due to greater electronegativity of the $\mathrm{N}$ atom than the $\mathrm{C}$ atom, whereas the resonance effect is electron-donating due to presence of n-electrons at the $\mathrm{N}$ atom. The n-electrons conjugate with $\pi$ electrons of the phenyl ring. The mixture of the inductive and resonance effects of the $\mathrm{NH}_{2}$ group differentiates the charge distribution at the phenyl $\mathrm{C}$ atoms. In the case of the neutral imine isomers 2-4, the exo=NH group also affects the phenyl ring (Scheme 4) but not in the same way as the $\mathrm{NH}_{2}$ group for $\mathbf{1}$. Both, the inductive and resonance effects of the $=\mathrm{NH}$ group are electron-accepting. The orientation of the imine $\mathrm{H}$ atom and possible intramolecular interactions (repulsion of the $\mathrm{CH}$ and $\mathrm{NH}$ groups, or interaction of the $\mathrm{CH}$ group with n-electrons of the $\mathrm{N}$ atom) additionally polarize $\pi$-electrons in the ring and influence the charge distribution at the phenyl $\mathrm{C}$ atoms. Taking the resonance structures of 1-4 into account, one can assume that the atom possessing the negative charge in the resonance structure may lose one electron and the atom possessing the positive charge may gain one electron during the oxidation and reduction process, respectively.

To obtain more information on the mechanism of oneelectron oxidation and one-electron reduction processes, the Mulliken charges, calculated for the neutral and redox

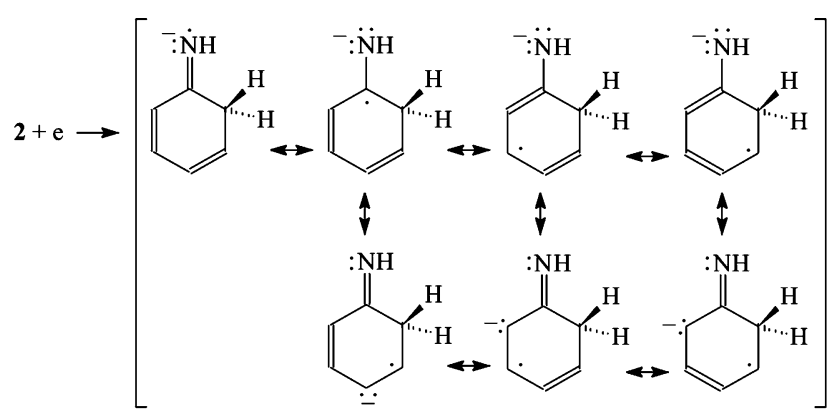

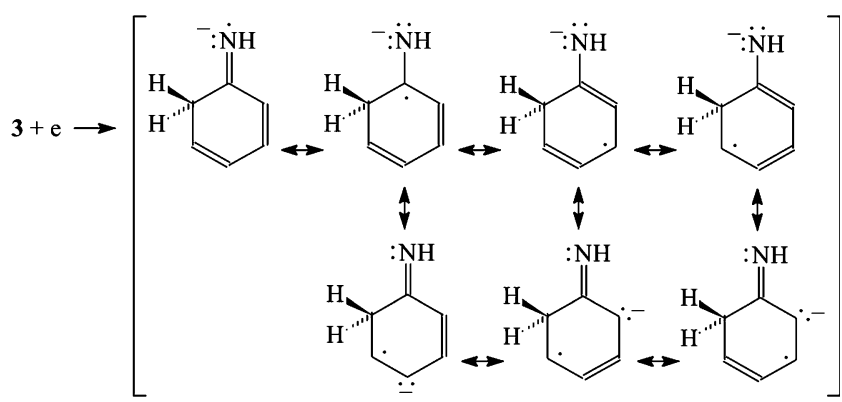

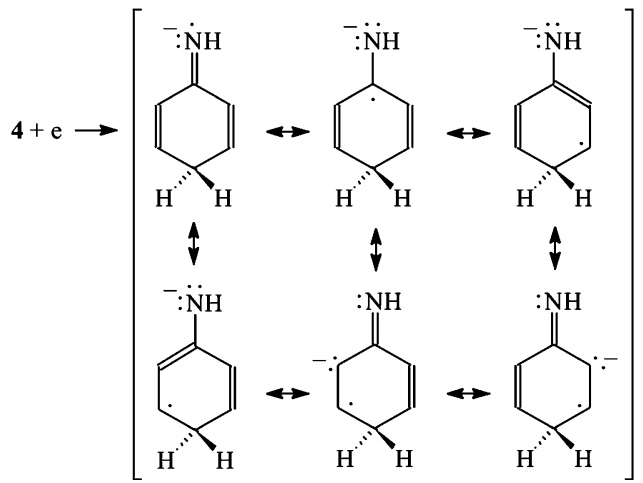

Scheme 8 Gain of one electron for the imine isomers $\mathbf{2} / \mathbf{3}$, and delocalization of electrons and negative charge for its radical anion 
forms of aniline at the B3LYP/6-311+G(d,p) level, are compared in Table 6. The comparison shows that for all neutral forms (1-4), the $\mathrm{N}$ atom possesses the negative Mulliken charge. For the $\mathrm{C}-\mathrm{sp}^{2}$ atoms, the Mulliken charges are negative or positive according to various effects of the $-\mathrm{NH}_{2} /=\mathrm{NH}$ group. For the $\mathrm{C}-\mathrm{sp}^{3}$ atom, which takes the moving proton $\left(\mathrm{C} 2 / \mathrm{C} 6-\mathrm{sp}^{3}\right.$ in $\mathbf{2} / \mathbf{3}$ and $\mathrm{C} 4-\mathrm{sp}^{3}$ in 4), its charge becomes more negative. This increase of the negative charge at ortho- and paraposition may partially explain the mechanisms of electrophilic substitutions of aniline $[6,7]$ and possible participation of the imine forms as intermediates. When proceeding from the neutral form to the radical cation, the negative charge of the $\mathrm{C}-\mathrm{sp}^{3}$ atom additionally augments. Great changes of the Mulliken charges $(\Delta$ values) take also place for the $\mathrm{N}$ atom which loses partially its negative charge in the radical cation isomers. This may suggest that during oxidation the $\mathrm{N}$ atom loses one electron from its n-orbital. However, an increase of the positive charge for some $\mathrm{C}$ atoms may also indicate that the $\mathrm{C}$ atom loses one electron from its $\pi$-orbital.

Indeed, for the enamine radical cation isomer 1 , the $\Delta$ values are positive for the $\mathrm{N} 7$ atom and also for all $\mathrm{C}$ atoms (with larger $\Delta$ values for the $\mathrm{C} 1$ and $\mathrm{C} 4$ atoms). Similar changes of the Mulliken charges $\{\mathrm{B} 3 \mathrm{LYP} / 6-311++\mathrm{G}(\mathrm{df}$, pd)\} have been observed by Michalska and co-workers [25]. These variations confirm a loss of one electron from the $\mathrm{n}$-orbital of the $\mathrm{N}$ atom as well as from the $\pi$-orbital of the ring $\mathrm{C}$ atom (Scheme 5). In the case of the imine radical cation isomers $\mathbf{2} / \mathbf{3}$, larger positive $\Delta$ values for the $\mathrm{N} 7, \mathrm{C} 1$, and $\mathrm{C} 3$ atoms suggest that one electron may be taken from the $\mathrm{n}$-orbital of the $\mathrm{N}$ atom. However, taking into account all possible resonance structures (Scheme 6), where unpaired electron is delocalized to the ring, one may also conclude that the $\mathrm{C}$ atom loses one electron from its $\pi$-orbital. Similar conclusion can be derived for the imine radical cation isomer 4 . The $\Delta$ values are positive for the $\mathrm{N} 7, \mathrm{C} 1, \mathrm{C} 3$, and $\mathrm{C} 5$ atoms, and they are negative for the $\mathrm{C} 2$ and C6. This indicates that one electron can be taken from the n-orbital of the $\mathrm{N}$ atom, and the positive charge can be delocalized at the N7, C1, C3, and C5 atoms (Scheme 6). For two resonance structures, unpaired electron is placed at the $\mathrm{C} 2$ or $\mathrm{C} 6$ atom. This may suggest that one electron may also be taken from the $\pi$-orbital of the $\mathrm{C}$ atom.

In the case of the radical anion isomers, the positive charge for the $\mathrm{N}$ atom of $\mathbf{1}$ suggests that this atom does not participate in electron gain, nor in delocalization of the negative charge. One excess electron seems to be taken by the phenyl ring (Scheme 7). The negative charge is delocalized at the $\mathrm{C} 1, \mathrm{C} 3$, and $\mathrm{C} 5$ atoms. Quite a different situation takes place for the imine forms (2-4). One-electron reduction increases the negative charge at the $\mathrm{C} 1, \mathrm{C} 3$, and $\mathrm{C} 5$ atoms and also at the $\mathrm{N} 7$ atom. This indicates that the $\pi$ - $\pi$ conjugated fragment, $-\mathrm{C}=\mathrm{C}-\mathrm{C}=\mathrm{C}-\mathrm{C}=\mathrm{NH}$ in $\mathbf{2 a} / \mathbf{3} \mathbf{a}$ and $\mathbf{2 b} / \mathbf{3 b}$ and $-(\mathrm{C}=\mathrm{C}-)_{2} \mathrm{C}=\mathrm{NH}$ in $\mathbf{4}$, gains the excess electron (Scheme 8).

\section{Conclusions}

Quantum-chemical calculations performed for the neutral, oxidized, and reduced enamine and imine forms of aniline (Scheme 1) showed evidently that one-electron oxidation does not change the tautomeric preference in the gas phase. The enamine tautomer $\mathbf{1}$ predominates for the oxidized mixture, similarly as for the neutral one. $\pi$-Electron delocalization seems to play a principal role in tautomeric system and affects the tautomeric preference. However, for unknown reason, other internal effect changes this trend for the reduced mixture for which the less delocalized imine isomers $\mathbf{2 a} / \mathbf{3 a}(89 \%)$ and $\mathbf{2} \mathbf{b} / \mathbf{3} \mathbf{b}(11 \%)$ dominate. This variation of the tautomeric preference and $\pi$-electron delocalization may be helpful in understanding the mechanisms of spontaneous point mutations in DNA [64-66] as well as the mechanisms of aniline oxidation polymerization and polycondensation [52-62].

Acknowledgements EDR thanks Dr. M. Makowski (University of Gdansk, Poland) for some kind of help.

Open Access This article is distributed under the terms of the Creative Commons Attribution Noncommercial License which permits any noncommercial use, distribution, and reproduction in any medium, provided the original author(s) and source are credited.

\section{References}

1. Patai S (ed) (1982) The Chemistry of Amino, Nitroso, Nitro Compounds and their Derivatives. Wiley, New York

2. Patai S (ed) (1996) The Chemistry of Amino, Nitroso, Nitro and Related Groups, Supplement F2.Wiley, Chichester

3. Katritzky AR, Jug K, Oniciu DC (2001) Chem Rev 101:1421-1450

4. Balaban AT, Oniciu DC, Katritzky AR (2004) Chem Rev 104:2777-2812

5. Raczyńska ED, Kosińska W, Ośmiałowski B, Gawinecki R (2005) Chem Rev 105:3561-3612

6. Carey FA, Sundberg RJ (1993) Advanced Organic Chemistry, 3rd edn. Plenum, New York

7. Lowry TH, Richardson KS (1987) Mechanism and Theory in Organic Chemistry. Harper \& Row, New York

8. Dunsch L (1975) J Electroanal Chem 61:61-80

9. Dunsch L (1996) J Electroanal Chem 419:55-59

10. Omelka L, Ondrášová S, Dunsch L, Petr A, Staško A (2001) Monatsh Chem 132:597-606

11. Pron A, Rannou P (2002) Prog Polym Sci 27:135-190

12. Kim Y, Fukai S, Kobayashi N (2001) Synth Met 119:337-338

13. Karunakaran C, Senthilvelan S (2006) Electrochem Commun $8: 95-101$, and references cited therein

14. Koval'chuk EP, Whittingham S, Skolozdra OM, Zavalij PY, Zavaliy IYu, Reshetnyak OV, Błażejowski J (2001) Mater Chem Phys 70:38-48 
15. Song X, Yang M, Davidson ER, Reilly JP (1993) J Chem Phys 99:3224-3233

16. Müller-Dethlefs K, Schlag EW (1991) Annu Rev Phys Chem 42:109-136

17. Piest H, von Helden G, Meijer G (1999) J Chem Phys 110:20102015

18. Gée C, Douin S, Crépin C, Bréchignac P (2001) Chem Phys Lett 338:130-136

19. Nakanaga T, Piracha NK, Ito F (2001) J Phys Chem A 105:42114215

20. McLafferty FW, Tureček F (1993) Interpretation of Mass Spectra. University Science Books, Mill Valley, California

21. Perrin CL (1977) J Am Chem Soc 99:5516-5518

22. Bunnett JF (1978) Acc Chem Res 11:413-420

23. Alder RW (1980) J Chem Soc Chem Commun 1184-1186

24. Ebersen L, Jönsson L, Wistrand LG (1982) Tetrahedron 38:10871093, and references cited therein

25. Wojciechowski PM, Zierkiewicz W, Michalska D, Hobza P (2003) J Chem Phys 118:10900-10911

26. Le HT, Flammang R, Barbieux-Flammang M, Gerbaux P, Nguyen MT (2002) Int J Mass Spectrom 217:45-54

27. Chyall LJ, Kenttämaa HI (1994) J Am Chem Soc 116:3135-3136

28. Chyall LJ, Kenttämaa HI (1995) J Mass Spectrom 30:81-87

29. Par RG, Yang W (1989) Density Functional Theory of Atoms and Molecules. Oxford University Press, New York

30. Becke AD (1993) J Chem Phys 98:5648-5652

31. Lee C, Yang W, Parr RG (1988) Phys Rev B 37:785-789

32. Bertrand W, Bouchoux G (1998) Rapid Commun Mass Spectrom 12:1697-1700

33. Rodríguez-Santiago L, Vendrell O, Tejero I, Sodupe M, Bertran J (2001) Chem Phys Let 334:112-118

34. Exner O, Bohm S (2006) Collect Czech Chem Commun 71:12391255

35. Raczyńska ED, Zientara K, Kolczyńska K, Stępniewski TM (2009) Pol J Chem 83:821-834

36. Raczyńska ED, Kamińska B (2010) J Phys Org Chem 23:828-835

37. Hehre WJ, Radom L, Schleyer PvR, Pople JA (1986) Ab initio Molecular Theory. New York

38. Curtiss LA, Raghavachari K, Trucks WG, Pople JA (1991) J Chem Phys 94:7221-7230

39. Curtiss LA, Raghavachari K, Pople JA (1993) J Chem Phys 98:1293-1298

40. Smith BJ, Radom L (1993) J Am Chem Soc 115:4885-4888

41. Smith BJ, Radom L (1995) J Phys Chem 99:6468-6471

42. Woon DE, Dunning TH (1993) J Chem Phys 98:1358-1371

43. Frisch MJ, Trucks GW, Schlegel HB, Scuseria GE, Robb MA, Cheeseman JR, Montgomery JA, Vreven T, Kudin KN, Burant JC, Millam JM, Iyengar SS, Tomasi J, Barone V, Mennucci B, Cossi M, Scalmani G, Rega N, Petersson R, Nakatsuji H, Hada M, Ehara M, Toyota K, Fukuda R, Hasegawa J, Ishida M, Nakajima T, Honda Y, Kitao O, Nakai H, Klene M, Li X, Knox JE, Hratchian HP, Cross JB, Bakken V, Adamo C, Jaramillo R,
Gomperts R, Stratmann RE, Yazyev O, Austin AJ, Cammi R, Pomelli C, Ochterski JW, Ayala PY, Morokuma K, Voth GA, Salvador P, Dannenberg JJ, Zakrzewski VG, Dapprich S, Daniels $\mathrm{AD}$, Strain MC, Farkas O, Malick DK, Rabuck AD, Raghavachari K, Foresman JB, Oritz JV, Cui Q, Baboul AG, Clifford S, Cioslowski J, Stefanov BB, Liu G, Liashenko A, Piskorz P, Komaromi I, Martin RL, Fox DJ, Keith T, Al-Laham MA, Peng CY, Nanayakkara A, Challacombe M, Gill PMW, Johnson B, Chen W, Wong MW, Gonzalez C, Pople JA (2004) Gaussian-03, Revision E.01. Gaussian, Inc, Wallingford CT

44. Lister DG, Tyler JK, Hög JH, Larsen NW (1974) J Mol Struct 23:253-264

45. Raczyńska ED, Krygowski TM, Duczmal K, Hallmann M (2006) XVIII International Conference on Physical Organic Chemistry, Warsaw, Book of abstracts, p. 31

46. Raczyńska ED, Hallmann M, Kolczyńska K, Stępniewski TM (2001) Symmetry 2:1485-1509

47. Krygowski TM (1993) J Chem Inf Comput Sci 33:70-78

48. Lammertsma K, Prasad BV (1994) J Am Chem Soc 116:642-650

49. Hehre WJ, Taylor RT, Pople JA, Schleyer PvR (1974) J Am Chem Soc 96:7162-7163

50. Schleyer PvR, Pühlhofer F (2002) Org Lett 4:2873-2876

51. Henriksen J, Hammerum S (1998) Int J Mass Spectrom 179/ 180:301-308

52. Genies EM, Lapkowski M (1987) J Electroanal Chem 236:189197

53. Lapkowski M, Genies EM (1990) J Electroanal Chem 279:157168

54. MacDiarmid AG, Epstein AI (1989) Faraday Discuss Chem Soc $88: 317-332$

55. Koval'chuk EP, Whittingham S, Skolozdra OM, Zavalij PY, Zavalij IYu, Reshetnyak OV, Seledets M (2001) Mater Chem Phys 69:154-162

56. Ćirić-Marjanović G, Konyushenko EN, Trchová M, Stejskal J (2008) Synth Met 158:200-211

57. de Barros RA, Areias MCC, de Azevedo WM (2010) Synth Met 160:61-64, and references cited therein

58. Madathil R (2005) Synth Met 150:123-126

59. Cristovan FH, Lemos SG, Santos JS, Trivinho-Strixino F, Pereira EC, Mattoso LHC, Kulkarni R, Manohar SK (2010) Electrochim Acta 55:3974-3978, and references cited therein

60. Santhanam M, Ramakrishnan V (1968) Indian J Chem 6:88-90

61. Santhanam M, Ramakrishnan V (1972) Indian J Chem 10:927928

62. Davidson RS, Lambeth PF, Santhanam M (1972) J Chem Soc Perkin Trans 2:2351-2355

63. Mallard WG, Linstrom PJ (eds) (2005) NIST Chemistry WebBook. NIST Standard Reference Database. National Institute of Standards and Thechnology, Gaithersburg, MD

64. Kryachko ES (2002) Int J Quantum Chem 90:910-923

65. Müller-Dethlefs K, Hobza P (2000) Chem Rev 100:143-168

66. Grebneva HA (2003) J Mol Struct 645:133-143 